\title{
In Vivo Stem Cell Imaging
}

\author{
Chunlei Zhao ${ }^{1,2,3,4}$, Mei Tian ${ }^{*}, 5$ and Hong Zhang ${ }^{*}, 1,2,3,4$ \\ ${ }^{I}$ Department of Nuclear Medicine, Second Affiliated Hospital of Zhejiang University, Hangzhou, China \\ ${ }^{2}$ Zhejiang University Medical PET Center, Hangzhou, China \\ ${ }^{3}$ Institute of Nuclear Medicine and Molecular Imaging of Zhejiang University, Hangzhou, China \\ ${ }^{4}$ Key Laboratory of Medical Molecular Imaging of Zhejiang Province, Hangzhou, China \\ ${ }^{5}$ Department of Experimental Diagnostic Imaging, The University of Texas M.D. Anderson Cancer Center, Houston, TX, \\ USA
}

\begin{abstract}
In recent years, the emerging and advances of non-invasive in vivo stem cell imaging has significantly contributed to the real-time tracking of transplanted stem cells as well as monitoring their proliferation, migration and persistence in live animals and ultimately possibly in humans. This review summarized the different in vivo imaging modalities for imaging stem cell, especially for its monitoring viability, death and proliferation; and discussed the strategies of combined multimodality approaches for monitoring of the fate of transplanted stem cell by offering the opportunity to distinguish different biological and biochemical processes.
\end{abstract}

Keywords: Stem cell, molecular imaging, magnetic resonance imaging, positron emission tomography, fluorescent probes.

\section{INTRODUCTION}

Stem cells can be classified as embryonic stem (ES) cells, fetal multipotent stem cells or adult stem cells (found in developed tissue, including brain, fat, skin, kidney, peripheral blood, bone marrow) and progenitor cells based on their origin during development or their location in the body [1]. Being with the potential of differentiation, stem cell has been increasingly attractive in regenerative therapies such as the treatment of Parkinson's disease, Alzheimer's disease, myocardial infarction, leukemia, diabetes, and other degenerative disorders $[2,3]$. After the systemic or local transplantation, stem cells and progenitor cells may be able to migrate and repopulate in pathologic sites to bring tremendous therapeutic effect [2]. However, risk may happen for the misbehavior following the stem cell transplantation, for example, teratoma formation by undifferentiated ES cell in case of human ES cell transplantation [4-6]. Therefore, in vivo tracking the fate of the transplanted stem cells over time is a vital step in determining the efficacy of the implant. For a long time, studies on stem cell mobility conventionally require histological investigation to determine viable engraftment of the transplanted cells. However, the inability to visualize cell populations in the same animal over time has been a major bottleneck in the in vivo evaluation of stem cell therapies because groups of animals have to be sacrificed at different time point for histology purpose [7].

In recent years, the emerging and advances of noninvasive in vivo stem cell imaging has significantly

*Address correspondence to this author at the (HZ) Department of Nuclear Medicine, Second Affiliated Hospital of Zhejiang University School of Medicine, 88 Jiefang Road, Hangzhou, Zhejiang 310009, China; Tel: 0086571-87767188; Fax: 0086-571-87767188; E-mail: hzhang21@gmail.com and (MT) The University of Texas M.D. Anderson Cancer Center, Houston, TX, USA contributed to the real-time tracking of grafted stem cells as well as monitoring their proliferation, migration and persistence in live animals and ultimately possibly in humans $[8,9]$. Usually, investigators manipulate cells ex vivo either by incorporating different exogenous imaging contrast agents or by transfecting different reporter genes. Stem cells carrying contrast agents (direct labeling) can be then detected by optical, magnetic resonance imaging (MRI) or radionuclide imaging methods, such as single photon emission computed tomography (SPECT) and positron emission tomography (PET) [10-15]. In contrast to direct labeling techniques, reporter gene techniques for stem cell labeling offer an attractive alternative because imaging signals are generated only from viable cells of interest. By sensitive imaging devices such as the optical coupled device, MRI, SPECT or PET, stem cells with the stably transfected imaging reporter genes can be detected with suitable imaging probes to visualize their distribution, to longitudinally monitor the cell survival and even to follow the successful differentiation of stem cells to mature functional cells in stem cell therapies $[5,9,16]$. Fig. (1) shows a schematic overview of stem cell imaging with reporter gene strategies.

Techniques available for in vivo molecular imaging so far include MR imaging [17], fluorescence and bioluminescence imaging [18, 19], SPECT and PET [20-22] based on their different principle (Table 1). These imaging modalities may provide distinctive, usually complementary information to the others. In this review, we will review mainstream stem cell imaging approaches on their characteristic aspects.

\section{MAGNETIC RESONANCE IMAGING}

MRI can provide high spatial resolution (ranging from $50 \mathrm{um}$ in animal and up to $300 \mathrm{um}$ in whole body clinical scanners), high temporal resolution and extract physiologic and anatomic information simultaneously $[12,16]$. Labeling 


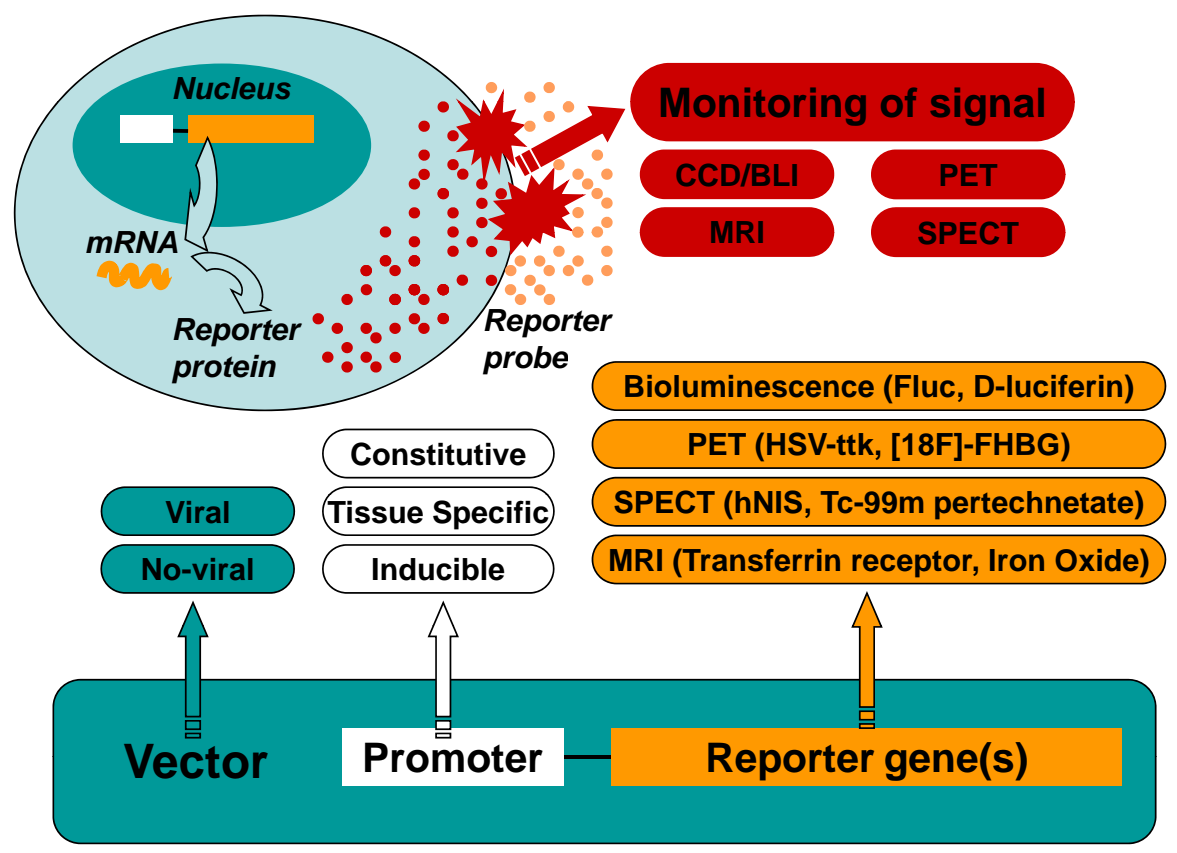

Fig. (1). Schematic overview of molecular imaging with reporter gene strategies. A vector containing a DNA reporter construct with the reporter gene(s) driven by a specific promoter. Transcription and translation lead to the expression of mRNA and reporter protein, respectively. After administration of a corresponding reporter probe systemically, the reporter probe will be catalyzed by specific cells that have the reporter proteins. The signals occurred in this amplification process can be detected by a sensitive imaging device. Examples of reporter genes and their specific reporter probes are delineated by imaging modality. Fluc, Firefly luciferase; PET, positron emission tomography; HSV-ttk, herpes simplex virus truncated thymidine kinase; [18F]-FHBG, 9-(4-[18F]-fluoro-3hydroxymethylbutyl) guanine; SPECT, single photon emission computed tomography; hNIS, human sodium/iodide symporter; MRI, magnetic resonance imaging; CCD, charged coupled device; BLI, bioluminescence imaging.

Table 1. Imaging Modalities of Stem Cell Trafficking

\begin{tabular}{|c|c|c|c|c|c|c|c|c|c|c|}
\hline $\begin{array}{c}\text { Imaging } \\
\text { Modality }\end{array}$ & $\begin{array}{c}\text { Spacial } \\
\text { Resolution }\end{array}$ & $\begin{array}{c}\text { Temporal } \\
\text { Resolution }\end{array}$ & Sensitivity & Depth & $\begin{array}{c}\text { Animal } \\
\text { Use }\end{array}$ & $\begin{array}{c}\text { Clinical } \\
\text { Use }\end{array}$ & Cost & Application & Advantages & Disadvantages \\
\hline \hline MRI & $1 \mathrm{~mm}$ & $\begin{array}{c}\text { Minutes to } \\
\text { hours }\end{array}$ & $10^{-3}-10^{-5} \mathrm{M}$ & No limit & Yes & Yes & Expensive & $\begin{array}{c}\text { Anatomical, } \\
\text { functional, } \\
\text { molecular }\end{array}$ & $\begin{array}{c}\text { High spacial } \\
\text { resolution, no } \\
\text { radiation }\end{array}$ & $\begin{array}{c}\text { Low sensitivity, } \\
\text { signal may not } \\
\text { reflect viable cells }\end{array}$ \\
\hline Bioluminescence & $3-5 \mathrm{~mm}$ & Minutes & $10^{-15}-10^{-17} \mathrm{M}$ & $\mathrm{cm}$ & Yes & No & Cheap & Molecular & High sensitivity & $\begin{array}{c}\text { Not clinically } \\
\text { applicable }\end{array}$ \\
\hline Fluorescence & $2-3 \mathrm{~mm}$ & Minutes & $10^{-9}-10^{-12}$ & $\mathrm{~cm}$ & Yes & No & Cheap & Molecular & High sensitivity & $\begin{array}{c}\text { Not clinically } \\
\text { applicable }\end{array}$ \\
\hline SPECT & $1-2 \mathrm{~mm}$ & $\begin{array}{c}\text { Minutes to } \\
\text { hours }\end{array}$ & $10^{-10}-10^{-12} \mathrm{M}$ & No limit & Yes & Yes & Expensive & $\begin{array}{c}\text { Functional, } \\
\text { molecular }\end{array}$ & $\begin{array}{c}\text { Sensitivity } 10- \\
\text { translational } \\
\text { capacity } \\
100 \text { times lower } \\
\text { than PET, } \\
\text { radiation } \\
\text { exposure }\end{array}$ \\
\hline PET & $1-2 \mathrm{~mm}$ & $\begin{array}{c}\text { Minutes to } \\
\text { weeks }\end{array}$ & $10^{-11}-10^{-12} \mathrm{M}$ & No limit & Yes & Yes & Expensive & $\begin{array}{c}\text { Anatomical, } \\
\text { functional, } \\
\text { molecular }\end{array}$ & $\begin{array}{c}\text { High sensitivity, } \\
\text { high biological } \\
\text { specificity }\end{array}$ \\
\hline
\end{tabular}

stem cells with magnetic agents for MRI is a suitable approach to monitor the distribution, migration, survival and differentiation when transplanted into animals over weeks in vivo $[1,12,13,23-25]$. By tracking labeled stem cell with MRI, it is helpful to establishing the optimal number of transplanted cells, define therapeutic windows and monitor cell growth and possible side effects for regenerative therapies [1]. MRI can also provide information about the surrounding tissue (edema, lesion size, inflammation) in addition to the information about grafted cell [1].
Stem cells should be labeled with contrast agents in advance before tracking with MRI. MR contrast agents contain metal ions, which define their relaxation properties. One type of contrast agents is the agent containing gadolinium-diethylenetriamine penta-acetic acid (GdDTPA), and the other type is the agent containing superparamagnetic iron oxide (SPIO) [26-30]. Paramagnetic metals such as gadolinium, iron and manganese mainly affect T1 relaxation. Whereas SPIO nanoparticles 
predominantly reduce $\mathrm{T} 2$ and $\mathrm{T} 2 *$ (due to the induction of strong field inhomogeneities) relaxation [31].

Contrast agents can be labeled to stem cell either by bounding to the external surface of the cell membrane by immunomagnetic linking to an antibody [1] or by internalizing into the cytoplasm through facilitated transmembrane uptake [32]. In the instance of immunomagnetic labeling, the contrast agent are not internalized into the cells, so they do not affect cell viability. However, the particles attached to the outer cell membrane are likely to interfere with cell-surface interactions and may easily detach from the membrane or be transferred to other cells [1]. Modified iron oxide particles such as dextran-coated SPIO nanoparticles, polycation-bound superparamagnetic iron oxide (PC-SPIO) and D-mannose-modified iron oxide nanoparticles are commonly used for intracellular magnetic labeling. These particles can provide efficient internalization with minimal deleterious effects on cellular functions [1, 32]. A study using human neural stem cells demonstrated that the biology of SPIO labeled stem cells, such as survival, migration, integration, and differentiation after transplantation is not altered in vitro and in vivo, making it possible to monitor the fate of the labeled stem cells in vivo under a variety of transplant conditions over time [25]. However, the influence of SPIO labeling on stem cell is still disputable because the impairment on the differentiation of SPIO labeled mesenchymal stem cells has also been found [33].

Combination of dextran-coated SPIO and transfection agent is a promising approach for stem cell labeling because transfection agents can effectively transport nanoparticles into cells through electrostatic interactions [1]. Other intracellular magnetic labeling strategies include the utilization of viral protein cages [34] and the use of internalizing monoclonal antibodies [26]. Compared to intracellular labeling, the average iron content per cell by immunomagnetic labeling was much lower (by two orders of magnitude) although sufficient MR contrast could be obtained [1]. Cells in suspension can be labeled using magnetoelectroporation [35]. Since exogenous markers such as SPIO particles are often degraded, diluted, and excreted as cell populations divide, it is not easy to assess the quantification and proliferation of stem cells in vivo by MRI [8].

Transferrin receptor (TfR) gene has been developed as a MR reporter gene for in vivo stem cell tracking. TfR can be highly expressed on the target cell membrane after transferring TfR gene to target cells. Binding with $\mathrm{Tf}$ protein, ultra small superparamagnetic oxides can enter cells through TfR and be detected by MRI as imaging probes [16]. Although efforts to develop suitable reporter genes for MRI have been done for years, the field is still in its early stage [36].

Stem cells labeled with Gd-DTPA can be monitored for only up to seven days after injection. Accordingly, GdDTPA labeled stem cell is not suitable for long term monitoring [37]. Whereas SPIO labeled stem cells are more appropriate for long-term in vivo monitoring because of the stability and high contrast of SPIO [26, 38]. However, MRI cannot specifically distinguish viable from nonviable cells or proliferating from nonproliferating cell populations, also cannot distinguish iron-labeled cells from free iron released upon cell death [39]. Therefore, iron particle labeling should better be looked as a marker for high-resolution detection of cell location other than that for monitoring cell viability in MRI stem cell tracking [39].

SPIO labeled stem cells particles can be identified as hypointensities on T2-weighted spin echo and 3D gradientecho MR images as the iron shortens transverse proton relaxation times. However, hypointense signal has the fundamental drawback of the difficulty in distinguishing iron-labeled cells from the surrounding air, hemorrhage, necrosis, and macrophages [25].

A number of factors, such as the SPIO concentration per cell, the cell density once the cells integrate into the host, and intrinsic MRI parameters such as field strength, signal to noise ratio, pulse sequence, and acquisition parameters, affects the detection threshold of SPIO-labeled cells [37, 40]. Among them, dilution of SPIO during cell division and reduction of cell density during migration and integration are the most important cellular factors determining the detection thresholds of MRI and limit long-term observation of SPIOlabeled stem cells [25].

Stem cell imaging with MRI is still lacking progress. As mentioned above, the low detection sensitivities of the imaging contrast agents and molecular reactions, the undesirable pharmacokinetics of substrates, and difficulties associated with the interpretations of signal changes are main impediments to overcome [16].

\section{BIOLUMINESCENCE AND FLUORESCENCE IMAGING}

Transducing bioluminescent and fluorescent reporter genes to stem cells guarantee the in vivo long term optical tracking of the cells because these reporter gene can be expressed in all cell progeny without dilution [8, 41]. Bioluminescent and fluorescent imaging are simpler, cheaper, more convenient, more user friendly than other imaging modalities and high-throughput due to the ease of operation, short acquisition times (usually 10-60 s), and the capability for simultaneous measurement $[6,16]$.

Bioluminescence imaging (BLI) detects the emission of visible photons at specific wavelengths based on energydependent reactions catalyzed by luciferases. The light of bioluminescence typically has very broad emission spectra that frequently extend beyond $600 \mathrm{~nm}$, with the red components of the emission spectra being the most useful for imaging by virtue of easy transmission through tissues [42]. Based on the high sensitivity of liquid cooled CCD cameras and the absence of background light emission caused by external illumination, bioluminescent imaging has great sensitivity to detect low levels of gene expression [16]. Firefly luciferase (Fluc), click beetle luciferase, Renilla luciferase (Rluc) and Gaussia luciferase (Gluc) are commonly used bioluminescence reporter gene for real-time stem cell tracking and Fluc is the most widely used one [16, 42]. By administering nontoxic substrate solution intravenously or intraperitoneally, bioluminescent images can be obtained within minutes [16]. The location, proliferation, migration, magnitude, and survival duration of stem cells of various origins have been monitored noninvasively in vivo using bioluminescent reporter genes, such as in brain [43, 44] and heart [5, 45]. A close 
relationship has been verified between cell numbers and biluminescence imaging signals [4, 5, 7, 46]. However, compared with other modalities such as MRI [8] and intravital microscopy (IVM) which can offers higher spatial resolution at a single-cell resolution [41], bioluminescence so far is still limited by a lower spatial resolution and unable to produce 3-dimensional and tomographic images because of attenuation of photons within tissues [39] although efforts in novel system development has been made to improve the accuracy of quantification and spatial resolution [42, 47].

Different from bioluminescence imaging, fluorescence imaging generally uses a fluorescent protein that is excited by an external light source with a wavelength a little shorter than that of the emitted light [16]. Green fluorescence protein (GFP) gene is the most commonly used fluorescence biomarker, which can be easily introduced into virtually any cell type using standard transduction methods and stable cell lines with continuous GFP expression can be produced [42]. Fluorescence imaging offers the possibility to image proteins and mammalian cells expressing them rapidly and inexpensively. However, due to the very low tissue penetrance (1-2 $\mathrm{mm})$ of the excitation and emission wavelengths of GFP which are within the range of $500 \mathrm{~nm}$ and unacceptable amount of background signal caused by extrinsic excitation light, called autofluorescence, GFP reporter cannot be used to reliably track in vivo characteristics of transplanted stem cells [6, 16, 42, 48]. Many strategies for visualization of GFP in vivo have been designed. Fluorescence-mediated tomography (FMT) is an advanced method for acquiring fluorescent images of deeper targets [42]. With a novel system enabling 3-dimensional imaging of fluorescent probes in whole animals and in parallel with a 3-dimensional surface reconstruction algorithm. Garofalakis et al. improved the accuracy of quantitative three-dimensional reconstruction of fluorescence distribution and obtained a higher spatial resolution in a GFP-expressing transgenic mouse model [47]. However, in most cases, GFP-expressing tissue must often be exposed surgically for imaging [42]. New fluorescent proteins with long emission of near-infrared (NIR) wavelengths (700-900 $\mathrm{nm}$ ), which have lower tissue absorption coefficients, also has been developed [49]. Imaging in the NIR spectrum can maximize tissue penetrance in addition to minimizing the autofluorescence from nontarget tissue. Studies with activatable NIR fluorescence optical probes have shown that the fluorescence can be increased over several hundred-fold by enzyme specific activation of probes in an in vitro cell culture experiments [50]. However, so for the only available NIR fluorochromes for stem cell tracking are quantum dots or molecule chemicals, by intracellular labeling [51] and by bounding to the external surface of the cell membrane [52].

Combined use of bioluminescent and fluorescent gene can be complementary to each other. Fluorescent marker may serve to determine the efficiency of transduction, and the conjuncted bioluminescent marker, may serve as an in vivo cell tracking protein $[41,46]$. With these strategies, a study using lentiviral vectors transduced human neural stem cells (hNSCs) expressing fusions of fluorescent and bioluminescent proteins has been performed to study hNSC kinetics and migration to malignant brain tumors by dual bioluminescence imaging and IVM [41].
Because bioluminescent and fluorescent proteins expressed in transduced stem cell are foreign antigens, they may induce immune responses [53, 54]. However, a number of studies have demonstrated that there was no significant adverse effects on the biological properties such as viability, proliferation and differentiation of stem cells transduced with reporter genes including bioluminescence and fluorescence ones $[5,43,55,56]$.

Despite the limitations, molecular bioluminescence and fluorescence imaging may continue to play a key role by allowing efficient, noninvasive, and rapid assessments of transgene expression in preclinical models [57].

\section{RADIONUCLIDE IMAGING}

Radionuclide imaging or nuclear medicine techniques, which include SPECT and PET, allow the imaging of radiolabeled markers and their interaction with biochemical processes in living subjects. Due to their exquisite nanomolar $\left(<10^{-9} \mathrm{M}\right)$ sensitivity, SPECT and PET are able to measure biological processes at very low concentrations.

Various clinical applicable radionuclides have been used based on previously established protocols for leukocyte or thrombocyte scintigraphy. For stem cell trafficking with SPECT, three strategies have been used: direct labeling with a radiometal $[58,59]$, enzymatic conversion with retention of a radioactive substrate [60], and receptor-medicated binding [61]. ${ }^{99 \mathrm{~m}}$ Tc-HMPAO labeling of mononuclear cells indicated that cardiac engraftment of cells in a dynamic process: the radioactivity uptake by the heart was $5 \%$ at 2 hours and $1 \%$ at 18 hours after transcoronary cell transplantation in a patient with acute myocardial infarction [62]. Although bone marrow-derived mesenchymal stem cells labeled with ${ }^{99 m} \mathrm{Tc}$ were successfully visualized up to 4 hours after cell infusion in a rat model of myocardial infarction [63], limitation of this technique include the trade-off between half-life and long-term exposure to ionizing radiation as well as potential of the radiometal transfer to non-stem cells must be taken into consideration. The technique of enzymatic conversion with retention of a radioactive substrate has been used for both SPECT and PET imaging, which uses introduction of the enzyme through a transgene. The significant advantage of this approach is the ability to follow stem cells indefinitely after stable integration of the transgene as well as the absence of dilution by cell division [64]. Genetically engineered receptor-mediated binding is conditional on stable expression of receptor not found elsewhere in the body and intravenous injection of the radioactive receptor ligand [61]. SPECT provides the advantages of cell quantification, a lower background signals, but also has disadvantage of a lower spatial resolution compared with MRI and optical imaging [65].

PET has a higher sensitivity than SPECT and permits more accurate quantification of cell numbers. The above mentioned three stem cell tracking strategies used in SPECT can be readily used for PET. By direct bone marrow cell (BMC) labeling, the initial clinical study was performed by using ${ }^{18}$ F-FDG PET imaging. In this study, unselected BMCs were radiolabeled with ${ }^{18} \mathrm{~F}$-FDG and infused into the infarctrelated coronary artery or injected via an antecubital vein. After intracoronary transfer, $1.3 \%$ to $2.6 \%$ of ${ }^{18} \mathrm{~F}-\mathrm{FDG}-$ labeled unselected BMCs were detected in the infarcted 
myocardium; the remaining activity was found primarily in liver and spleen. However, only background activity was detected in the infarcted myocardium after intravenous transfer. Unselected BMCs engrafted in the infarct center and border zone [66]. With immunomagnetically enriched CD34-positive cells, $14 \%$ to $39 \%$ of total injected radioactivity was detected in infarcted myocardium after intracoronary injections, preferentially in the border zone. A similar clinical tracking study using ${ }^{18}$ F-FDG labeled peripheral hematopoietic stem cells has also been reported in patients with myocardial infarction [67]. However, due to the limitation of short half-life of ${ }^{18} \mathrm{~F}$, direct cell labeling with ${ }^{18}$ F-FDG could not assess cell trafficking and persistence days after therapeutic application.

Reporter gene approaches have many advantages over direct and indirect cell labeling methods. Stable transfection of cells ensure for long term expression of the reporter gene that does not dilute out in proliferating cells. Furthermore, over time accumulated divided cells can generate increased signal that can be detected with repeated imaging [68]. In addition, the signals detected prove the in vivo presence of viable cells [69]. Currently, one of the most widely used reporter genes for PET imaging is wild-type herpes simplex type 1 thymidine kinase (HSV1-tk) and its HSV1-sr39tk mutant. This enzyme efficiently phosphorylates purine and pyrimidine analogs and has been very successfully used with radio-labeled reporter probes such as ${ }^{124} \mathrm{I}-2^{\prime}$-fluoro-2'-deoxy$1-\beta$-D- $\beta$-arabinofuranosyl-5- iodouracil (FIAU), ${ }^{18} \mathrm{~F}-2^{\prime}-$ fluoro- 2 -deoxy-1- $\beta$-D- $\beta$-arabinofuranosyl-5-ethyluracil

(FEAU) and ${ }^{18}$ F-9-(4- ${ }^{18}$ F-fluoro-3-hydroxymethyl-butyl) guanine (FHBG) $[5,70,71]$. One of the advantages of enzymatic reporter gene systems, such as -tk enzyme, is the signal amplification that occurs as a result of imaging probe trapping and accumulation. This signal amplification is generally not generated by receptor and transporter based reporters. However, the major limitation for successful translation of HSV-tk reporter gene into clinical setting is the immune reaction that the viral protein elicits in humans [69, 72]. Although reporter gene imaging permits tracking and quantification of stem cells over the course of many months, certain prerequisites might hamper immediate clinical applicability of this strategy: ex vivo genetic manipulation of the cells, an infrastructure for ${ }^{18} \mathrm{~F}$ chemistry, a PET scanner, and radiation exposure to the stem cells and subject. Finally, additional drawbacks with PET (as well as SPECT) imaging include nonspecific uptake of the radiotracer by normal tissues, such as liver or kidney, and non-negligible tissue photon attenuation. Despite bearing a conceptual promise, the use of reporter-gene imaging to monitor cell transplantation is still limited to animal model studies except for one recent clinical report [73]. In order to proceed from bench to bedside, further work is required to develop nonimmunogenic probes, improve transfection stability, and reduce the interference of transfection with the cell function and desired molecular effect. Strength of the imaging signal is critical, and additional work is necessary to establish a robust approach for cell visualization that is also practical for use in the clinical setting [65].

\section{MULTIMODALITY IMAGING}

Combined multimodality approaches are novel strategies that allow the monitoring of the fate of transplanted stem cells by offering the opportunity to distinguish different biological and biochemical process in a single animal. Various combinations, such as double fusion of bioluminescence and fluorescence reporter gene $[5,55]$, double fusion of different bioluminescence reporter genes [74-76], co-labeling with reporter gene and iron particles [39], and triple fusion of the fusion of fluorescence, bioluminescence and PET reporter genes [46] have been developed for in vivo stem cell tracking. Multimodal systems containing MRI reporter gene might be helpful because the images of MRI reporter gene expression with high resolution may be perfectly complementary to PET or bioluminescent and fluorescent images with high sensitivity [16]. In many respects the techniques are complementary; there is no "allin-one" imaging modality providing optimal sensitivity, specificity and temporo-spatial resolution. Novel combined multimodality approaches, such as PET-MRI, PET-CT, PET-optical imaging, etc., may be designed in the future as a more suitable approach for monitoring the spatial and temporal kinetics of transplanted stem cells in living subjects in vivo.

\section{CONCLUSION}

Reporter gene imaging using PET is a better technique for monitoring long-term cell viability, death, and proliferation, whereas MR imaging is a better technique for high-resolution detection of cell location post-transplantation [39]. Bioluminescent imaging should be seen as the one that is possibly complementary to other modalities such as MRI in which higher resolution is required [8]. To confirm the fate of stem cells in vivo, it is crucial to continue the development and further refinement of noninvasive imaging techniques.

\section{ACKNOWLEDGEMENTS}

This work was partly sponsored by grants from the National Science Foundation of China (NSFC) (No. 30672396) and the Ministry of Science and Technology of China (No.2006DFB32940, 2011CB504400).

\section{REFERENCES}

[1] Sykova E, Jendelova P. Migration, fate and in vivo imaging of adult stem cells in the cns. Cell Death Differ 2007; 14: 1336-42.

[2] Acton PD, Zhou R. Imaging reporter genes for cell tracking with PET and SPECT. Quart J Nucl Med Mol Imaging 2005; 49: 34960.

[3] Chiu RC. Bone-marrow stem cells as a source for cell therapy. Heart Fail Rev 2003; 8: 247-51.

[4] Li Z, Wu JC, Sheikh AY, et al. Differentiation, survival, and function of embryonic stem cell derived endothelial cells for ischemic heart disease. Circulation 2007; 116: 46-54.

[5] Cao F, Lin S, Xie X, et al. In-vivo visualization of embryonic stem cell survival, proliferation, and migration after cardiac delivery. Circulation 2006; 113: 1005-14.

[6] van der Bogt KE, Swijnenburg RJ, Cao F, et al. Molecular imaging of human embryonic stem cells: Keeping an eye on differentiation, tumorigenicity and immunogenicity. Cell Cycle 2006; 5: 2748-52.

[7] Chang GY, Xie X, Wu JC. Overview of stem cells and imaging modalities for cardiovascular diseases. J Nucl Cardiol 2006; 13: 554-69.

[8] Kim DE, Schellingerhout D, Ishii K, et al. Imaging of stem cell recruitment to ischemic infarcts in a murine model. Stroke 2004; 35: $952-7$.

[9] Serganova I, Blasberg R. Reporter gene imaging: Potential impact on therapy. Nucl Med Biol 2005; 32: 763-80. 
[10] Norman AB, Thomas SR, Pratt RG, et al. Magnetic resonance imaging of neural transplants in rat brain using a superparamagnetic contrast agent. Brain Res 1992; 594: 279-83.

[11] Hawrylak N, Ghosh P, Broadus J, et al. Nuclear magnetic resonance (NRM) imaging of iron oxide-labeled neural transplants. Exp Neurol 1993; 121: 181-92.

[12] Suzuki Y, Zhang S, Kundu P, et al. In vitro comparison of the biological effects of three transfection methods for magnetically labeling mouse embryonic stem cells with ferumoxides. Magn Reson Med 2007; 57: 1173-9.

[13] Stuckey DJ, Carr CA, Martin-Rendon E, et al. Iron particles for noninvasive monitoring of bone marrow stromal cell engraftment into, and isolation of viable engrafted donor cells from, the heart. Stem Cells 2006; 24: 1968-75.

[14] Cui J, Wahl RL, Shen T, et al. Bone marrow cell trafficking following intravenous administration. Br J Haematol 1999; 107: 895-902.

[15] Lanzkron SM, Collector MI, Sharkis SJ. Hematopoietic stem cell tracking in vivo: A comparison of short-term and long-term repopulating cells. Blood 1999; 93: 1916-21.

[16] Kang JH, Chung JK. Molecular-genetic imaging based on reporter gene expression. J Nucl Med 2008; 49(Suppl 2): 164S-79S

[17] Modo M, Hoehn M, Bulte JW. Cellular MR imaging. Mol Imaging 2005; 4: 143-64.

[18] Chaudhari AJ, Darvas F, Bading JR, et al. Hyperspectral and multispectral bioluminescence optical tomography for small animal imaging. Phys Med Biol 2005; 50: 5421-41.

[19] Mizrahi $\mathrm{A}$, $\mathrm{Lu} \mathrm{J}$, Irving $\mathrm{R}$, et al. In-vivo imaging of juxtaglomerular neuron turnover in the mouse olfactory bulb. Proc Natl Acad Sci USA 2006; 103: 1912-7.

[20] Adonai N, Nguyen KN, Walsh J, et al. Ex-vivo cell labeling with ${ }^{64} \mathrm{Cu}$-pyruvaldehyde-bis (n4-methylthiosemicarbazone) for imaging cell trafficking in mice with positron-emission tomography. Proc Natl Acad Sci USA 2002; 99: 3030-5.

[21] Huang J, Lee CC, Sutcliffe JL, et al. Radiolabeling rhesus monkey $\mathrm{CD} 34+$ hematopoietic and mesenchymal stem cells with ${ }^{64} \mathrm{Cu}-$ pyruvaldehyde-bis(n4-methylthiosemicarbazone) for micro-PET imaging. Mol Imaging 2008; 7: 1-11.

[22] Hung SC, Deng WP, Yang WK, et al. Mesenchymal stem cell targeting of microscopic tumors and tumor stroma development monitored by noninvasive in-vivo positron emission tomography imaging. Clin Cancer Res 2005; 11: 7749-56.

[23] Kraitchman DL, Heldman AW, Atalar E, et al. In-vivo magnetic resonance imaging of mesenchymal stem cells in myocardial infarction. Circulation 2003; 107: 2290-3.

[24] Himes N, Min JY, Lee R, et al. In-vivo MRI of embryonic stem cells in a mouse model of myocardial infarction. Magn Reson Med 2004; 52: 1214-9.

[25] Guzman R, Uchida N, Bliss TM, et al. Long-term monitoring of transplanted human neural stem cells in developmental and pathological contexts with MRI. Proc Natl Acad Sci USA 2007; 104: 10211-6.

[26] Bulte JW, Zhang S, van Gelderen P, et al. Neurotransplantation of magnetically labeled oligodendrocyte progenitors: Magnetic resonance tracking of cell migration and myelination. Proc Natl Acad Sci USA 1999; 96: 15256-61.

[27] Lewin M, Carlesso N, Tung $\mathrm{CH}$, et al. Tat peptide-derivatized magnetic nanoparticles allow in vivo tracking and recovery of progenitor cells. Nat Biotechnol 2000; 18: 410-4.

[28] Bulte JW, Douglas T, Witwer B, et al. Magnetodendrimers allow endosomal magnetic labeling and in vivo tracking of stem cells. Nat Biotechnol 2001; 19: 1141-7.

[29] Modo M, Cash D, Mellodew K, et al. Tracking transplanted stem cell migration using bifunctional, contrast agent-enhanced, magnetic resonance imaging. Neuroimage 2002; 17: 803-11.

[30] Bulte JW, Duncan ID, Frank JA. In vivo magnetic resonance tracking of magnetically labeled cells after transplantation. J Cereb Blood Flow Metab 2002; 22: 899-907.

[31] Wood ML, Hardy PA. Proton relaxation enhancement. J Magn Reson Imaging 1993; 3: 149-56.

[32] Arbab AS, Yocum GT, Wilson LB, et al. Comparison of transfection agents in forming complexes with ferumoxides, cell labeling efficiency, and cellular viability. Mol Imaging 2004; 3: 2432.
[33] Kostura L, Kraitchman DL, Mackay AM, et al. Feridex labeling of mesenchymal stem cells inhibits chondrogenesis but not adipogenesis or osteogenesis. NMR Biomed 2004; 17: 513-7.

[34] Allen M, Bulte JW, Liepold L, et al. Paramagnetic viral nanoparticles as potential high-relaxivity magnetic resonance contrast agents. Magn Reson Med 2005; 54: 807-12.

[35] Walczak P, Kedziorek DA, Gilad AA, et al. Instant MR-labeling of stem cells using magnetoelectroporation. Magn Reson Med 2005; 54: 769-74.

[36] Gilad AA, Winnard PT, Jr., van Zijl PC, et al. Developing MR reporter genes: Promises and pitfalls. NMR Biomed 2007; 20: 275 90.

[37] Chang NK, Jeong YY, Park JS, et al. Tracking of neural stem cells in rats with intracerebral hemorrhage by the use of 3T MRI. Korean J Radiol 2008; 9: 196-204.

[38] Frank JA, Miller BR, Arbab AS, et al. Clinically applicable labeling of mammalian and stem cells by combining superparamagnetic iron oxides and transfection agents. Radiology 2003; 228: 480-7.

[39] Li Z, Suzuki Y, Huang M, et al. Comparison of reporter gene and iron particle labeling for tracking fate of human embryonic stem cells and differentiated endothelial cells in living subjects. Stem Cells 2008; 26: 864-73.

[40] Heyn C, Bowen CV, Rutt BK, et al. Detection threshold of single SPIO-labeled cells with fiesta. Magn Reson Med 2005; 53: 312-20.

[41] Shah K, Hingtgen S, Kasmieh R, et al. Bimodal viral vectors and in vivo imaging reveal the fate of human neural stem cells in experimental glioma model. J Neurosci 2008; 28: 4406-13.

[42] Shah K, Jacobs A, Breakefield XO, et al. Molecular imaging of gene therapy for cancer. Gene Ther 2004; 11: 1175-87.

[43] Tang Y, Shah K, Messerli SM, et al. In vivo tracking of neural progenitor cell migration to glioblastomas. Hum Gene Ther 2003; 14: $1247-54$

[44] Hwang do W, Kang JH, Jeong JM, et al. Noninvasive in-vivo monitoring of neuronal differentiation using reporter driven by a neuronal promoter. Eur J Nucl Med Mol Imaging 2008; 35: 135-45.

[45] Wu JC, Chen IY, Sundaresan G, et al. Molecular imaging of cardiac cell transplantation in living animals using optical bioluminescence and positron emission tomography. Circulation 2003; 108: 1302-5.

[46] Cao F, Drukker M, Lin S, et al. Molecular imaging of embryonic stem cell misbehavior and suicide gene ablation. Cloning Stem Cells 2007; 9: 107-17.

[47] Garofalakis A, Zacharakis G, Meyer H, et al. Three-dimensional in-vivo imaging of green fluorescent protein-expressing T-cells in mice with noncontact fluorescence molecular tomography. Mol Imaging 2007; 6: 96-107.

[48] Troy T, Jekic-McMullen D, Sambucetti L, et al. Quantitative comparison of the sensitivity of detection of fluorescent and bioluminescent reporters in animal models. Mol Imaging 2004; 3: 9-23

[49] Weissleder R. Scaling down imaging: Molecular mapping of cancer in mice. Nat Rev Cancer 2002; 2: 11-8.

[50] Tung $\mathrm{CH}$, Bredow S, Mahmood U, et al. Preparation of a cathepsin D sensitive near-infrared fluorescence probe for imaging. Bioconjug Chem 1999; 10: 892-6.

[51] Lei Y, Tang H, Feng M, et al. Applications of fluorescent quantum dots to stem cell tracing in-vivo. J Nanosci Nanotechnol 2009; 9: 5726-30.

[52] Park KS, Tae J, Choi B, et al. Characterization, in vitro cytotoxicity assessment, and in vivo visualization of multimodal, ritc-labeled, silica-coated magnetic nanoparticles for labeling human cord blood-derived mesenchymal stem cells. Nanomedicine 2010; 6(2): 263-76.

[53] Jeon YH, Choi Y, Kang JH, et al. Immune response to firefly luciferase as a naked DNA. Cancer Biol Ther 2007; 6: 781-6.

[54] Stripecke R, Carmen Villacres M, Skelton D, et al. Immune response to green fluorescent protein: Implications for gene therapy. Gene Ther 1999; 6: 1305-12.

[55] Wu JC, Cao F, Dutta S, et al. Proteomic analysis of reporter genes for molecular imaging of transplanted embryonic stem cells. Proteomics 2006; 6: 6234-49.

[56] Okada S, Ishii K, Yamane J, et al. In-vivo imaging of engrafted neural stem cells: Its application in evaluating the optimal timing of transplantation for spinal cord injury. FASEB J 2005; 19: 1839-41. 
[57] Iyer M, Sato M, Johnson M, et al. Applications of molecular imaging in cancer gene therapy. Curr Gene Ther 2005; 5: 607-18.

[58] Chin BB, Nakamoto Y, Bulte JW, et al. 111In-oxine labelled mesenchymal stem cell SPECT after intravenous administration in myocardial infarction. Nucl Med Commun 2003; 24: 1149-54.

[59] Blackwood KJ, Lewden B, Wells RG, et al. In-vivo SPECT quantification of transplanted cell survival after engraftment using 111 In-tropolone in infarcted canine myocardium. J Nucl Med 2009; 50: 927-35.

[60] Gambhir SS, Herschman HR, Cherry SR, et al. Imaging transgene expression with radionuclide imaging technologies. Neoplasia 2000; 2: 118-38.

[61] Simonova M, Shtanko O, Sergeyev N, et al. Engineering of technetium-99m-binding artificial receptors for imaging gene expression. J Gene Med 2003; 5: 1056-66.

[62] Penicka M, Widimsky P, Kobylka $\mathrm{P}$, et al. Images in cardiovascular medicine. Early tissue distribution of bone marrow mononuclear cells after transcoronary transplantation in a patient with acute myocardial infarction. Circulation 2005; 112: 63-5.

[63] Barbash IM, Chouraqui P, Baron J, et al. Systemic delivery of bone marrow-derived mesenchymal stem cells to the infarcted myocardium: Feasibility, cell migration, and body distribution. Circulation 2003; 108: 863-8.

[64] Hoshino K, Ly HQ, Frangioni JV, et al. In vivo tracking in cardiac stem cell-based therapy. Prog Cardiovasc Dis 2007; 49: 414-20.

[65] Beeres SL, Bengel FM, Bartunek J, et al. Role of imaging in cardiac stem cell therapy. J Am Coll Cardiol 2007; 49: 1137-48.

[66] Hofmann M, Wollert KC, Meyer GP, et al. Monitoring of bone marrow cell homing into the infarcted human myocardium. Circulation 2005; 111: 2198-202.

[67] Kang WJ, Kang HJ, Kim HS, et al. Tissue distribution of ${ }^{18}$ F-FDGlabeled peripheral hematopoietic stem cells after intracoronary administration in patients with myocardial infarction. J Nucl Med 2006; 47: 1295-301.
[68] Tian M, Perin E, Silva G, et al. Long-term monitoring of persistence, migration and differentiation of HSV1-tk expressed mesenchymal stem cells in an ischemia-reperfusion porcine model with ${ }^{18}$ F-FEAU PET/CT and MRI. Presentation at the World Congress of Molecular Imaging, Montreal, Canada 2009.

[69] Arbab AS, Janic B, Haller J, et al. In-vivo cellular imaging for translational medical research. Curr Med Imaging Rev 2009; 5: 19 38.

[70] Tjuvajev JG, Doubrovin M, Akhurst T, et al. Comparison of radiolabeled nucleoside probes (FIAU, FHBG, and FHPG) for PET imaging of HSV1-tk gene expression. J Nucl Med 2002; 43: 1072 83.

[71] Kang KW, Min JJ, Chen X, et al. Comparison of $\left[{ }^{14} \mathrm{C}\right] \mathrm{FMAU}$, $\left[{ }^{3} \mathrm{H}\right] \mathrm{FEAU},\left[{ }^{14} \mathrm{C}\right] \mathrm{FIAU}$, and $\left[{ }^{3} \mathrm{H}\right] \mathrm{PCV}$ for monitoring reporter gene expression of wild type and mutant herpes simplex virus type 1 thymidine kinase in cell culture. Mol Imaging Biol 2005; 7: 296303.

[72] Krishnan M, Park JM, Cao F, et al. Effects of epigenetic modulation on reporter gene expression: Implications for stem cell imaging. FASEB J 2006; 20: 106-8.

[73] Yaghoubi SS, Jensen MC, Satyamurthy N, et al. Noninvasive detection of therapeutic cytolytic T- cells with ${ }^{18} \mathrm{~F}$-FHBG PET in a patient with glioma. Nat Clin Pract Oncol 2009; 6: 53-8.

[74] Bhaumik S, Gambhir SS. Optical imaging of renilla luciferase reporter gene expression in living mice. Proc Natl Acad Sci USA 2002; 99: 377-82.

[75] Zhang $\mathrm{H}$, Zheng XS, Yang XF, et al. 11CNMSP/18F-FDG microPET to monitor neural stem cell transplantation in a rat mode of traumatic brain injury. Eur J Nucl Med Mol Imaging 2008; 35(9): 1699-708.

[76] Jiang $\mathrm{H}$, Cheng $\mathrm{Z}$, Tian $\mathrm{M}$, et al. In vivo imaging of embryonic stem cell therapy. Eur J Nucl Med Mol Imaging 2010; 10.1007/s0 0259-010-1667-y

This is an open access article licensed under the terms of the Creative Commons Attribution Non-Commercial License (http://creativecommons.org/licenses/by-nc/ $3.0 /$ ) which permits unrestricted, non-commercial use, distribution and reproduction in any medium, provided the work is properly cited. 